\title{
Available Transfer Capability Calculation
}

\author{
Mojgan Hojabri and Hashim Hizam \\ Universiti Putra Malaysia \\ Malaysia
}

\section{Introduction}

The maximum power that can be transferred from one area to another area is called transfer capability. In 1996, North American Electric Reliability Council (NERC) established a framework for Available Transfer Capability (ATC) definition and evaluation. According to the NERC definition, ATC is the transfer capability remaining between two points above and beyond already committed uses (NERC, 1996). The ATC value between two points is given as:

$$
A T C=T T C-T R M-C B M-E T C
$$

Where TTC is total transfer capability, TRM is transmission reliability margin, CBM is capacity benefit margin and ETC is existing transmission commitment including customer services between the same two points. In power marketing, the interconnected power system may comprise many areas corresponding to utilities. The operation of the system is reported to an Independent System Operator (ISO). The ISO may receive all demands of energy. All of energy demands may be accepted if they are less than ATC between two areas. ATC must also be calculated by ISO in real time for all the areas under its territory. Evaluating the risk of violation of the transfer capability, because of the random events such as random failures of power system equipments, is an important point that must be considered to compute the probability that transfer capability will not exceed the required value.

In 1992 the Federal Energy Regulatory Commission (FERC), after gathering the industrial comments, published a series of issues an electrical marketing. The orders No. 888 (NERC, 1996) and No 889 (FERC, 1996) are two famous issues of FERC which were presented in 1996. These orders provided key guidelines to energy market players for better competition in the US power market. FERC order 888 mandated the separation of electrical services and marketing functions to determine the standard price of energy for a better customer choice. FERC order 889 mandated the information of Available Transfer Capability (ATC) and Total Transfer Capability (TTC) of power utilities must be posted on the Open Access Same-time Information System (OASIS) (FERC, 1996). FERC order 2000 built upon the ISO concept by encouraging smaller transmission companies to join together into RTOs (Regional Transmission Organizations). Order 888, 889 and 2000 have included a lot of major milestones that have caused different kind of electrical market structures and business practices in US. ATC was explained by the FERC as the measure of remaining in the physical transmission network over committed uses. TTC is also 
determined as the total power that can be sent in a reliable way. The aim of ATC and TTC calculation and posting them to OASIS is to enhance the open access transmission system by making a market signal of the capability of a transmission system to deliver electrical energy.

North American Electric Reliability Council (NERC) proposed a numerical approximation of the ATC in 1995 and 1996 (NERC, 1995; NERC, 1996) According to the NERC definition, ATC is the difference between TTC and the sum of the Transmission Reliability Margin (TRM), Capability Benefit Margin (CBM), and the Existing Transmission Commitments (ETC). The real power transfer at the first security violation excluding existing transmission commitments is the total TTC. TRM is defined as the amount of the transmission transfer capability necessary to ensure that the interconnected network is secure under a reasonable range of uncertainties in system conditions. CBM is determined as the amount of TTC reserved by Load Serving Entities (LSE) to certify for power generating from transfer lines by considering generation reliability (NERC, 1996).

\subsection{Available transfer capability}

According to the NERC definition in Equation 1.1, utilities would have to determine adequately their ATCs to ensure that system reliability is maintained while serving a wide range of transmission transactions. ATC must be calculated, updated and reported continuously to LSE in normal and contingency situation. The ATC calculation must be covered all below principles (Sauer \& Grijalva, 1999):

1. Provide the logical and reliable indication of transfer capability.

2. Identification time-variant conditions, synchronous power transfers, and parallel flows.

3. Considering the dependence on points of injection / extraction.

4. Considering regional coordination.

5. Covering the NERC and other organizational system reliability criteria and guides.

6. Coordinate reasonable uncertainties in transmission system conditions and provide flexibility

Usually determination of transfer capability and other related margins has been coordinated by the North American Electric Reliability Council. Operating studies commonly seek to determine limitations due to the following types of problems (Merryl, 1998).

1. Thermal overloads Limitation

2. Voltage stability Limitation

3. Voltage limitation

4. Power generated Limitation

5. Reactive power generated Limitation

6. Load Power Limitation

Based on market demands, ATC is computed hourly, daily or monthly. In ATC calculations, definite factors such as contingencies that would represent most serious disturbances, unit commitment, accuracy of load forecast and distribution, system topology and configuration, and maintenance scheduling should be taken into account. System control devices such as voltage regulators and reactive power control devices also have a direct impact on ATC values. The literatures on ATC calculation can be divided into deterministic and probabilistic methods. Deterministic ATC calculation methods, determine ATC for definite time and certain environment. Straight forward implement, easy and fast are most 
important beneficial of using these methods. However these methods could not consider system uncertainties. The uncertainty is one of the important natures of the power system behavior to determine the ATC. In the regulated environment, weather factors, load forecast and fault of generators, lines and transformers have most effects on ATC estimation for planning system. Moreover they are increased since the uncertainty in bid acceptance procedures, customer response to prices and control of interruptible loads (Sakis Meliopoulos, Wook Kang, \& Cokkinides, 2000). These uncertainties must be quantified for the next few hours by ISO in real time. Therefore, probabilistic ATC calculation methods must be used to cover this problem.

\subsubsection{Review of previous works on deterministic methods}

Previous researches can give comprehensive information during the operational planning stage which is off-line executed shortly before the real-time operation, while the latter may provide timely relevant data to on-line operational performance. For on-line calculation, i.e. in an operation environment where ATC values are posted on a short-term (usually one to several hours or even shorter) basis, calculation of ATC may be performed for most limiting constraints. The methods of on line ATC calculation are based on deterministic model, and they may be solved by several methods, such as: DC Power Flow (DCPF), Power Transfer Distribution Factor (PTDF), Generation Shifting Factor (GSF), Repeated Power Flow (RPF), and Line Outage Distribution Factor (LODF), Continuation Power Flow (CPF), and Optimal Power Flow (OPF) methods.

DC Power Flow has been widely used to calculate thermal limit with great speed. However DC power flow cannot deal with other limiting factors. Distribution factors based on DC or AC power flow methods were proposed for calculating ATC in (Flueck, Chiang, \& Shah, 1996; Ilic, Yoon, \& Dept, 1997; Gisin, B.S, M.V., \& Mitsche, 1999; Li \& Liu, 2002; Venkatesh, R, \& Prasad, 2004; Ghawghawe, Thakre, \& L, 2006). Because of the relative ease, coupled with the mild computational burden involved in computing these factors, they have found widespread application in the industry (Hamoud, 2000). Power Transfer Distribution Factor (PTDF) using DC power flow and AC power flow are derived to calculate ATC. In DCPTDF method (Wood, 1996), DC load flow i.e. a linear model, is considered. These methods are fast but they are not accurate. ACPTDF was used by (Kumar, Srivastava, \& Singh, 2004) for determination of ATC of a practical system. It considers the determination of power transfer distribution factors, computed at a base case load flow using sensitivity properties of Newton Raphson Load Flow (NRLF) Jacobean. Line Outage Distribution Factor (LODF) describes the power flow change due to the outage of other branch. LODF can be obtained directly by DC power flow equation. It describes the branch power flow changes due to the power increase between the sending subsystem and receiving subsystem. In other words, it describes the power ratio of the monitored branch power changes with respect to the power change of the study transfer after single branch is outage. Therefore, LODF is valid for the network topology after single branch is outage. To compute the first contingency incremental transfer capability the LODF and PTDF was combined by (Yang \& Brent, 2001).

NEMMCO in Australia power market performs its constraint management and construct its constraint thermal equations by means of Generation Shift Factor (GSF). In terms of ISO-NE, it uses GSF and other linear distribution factors in a variety of planning and operating analyses, including the determination of available transfer capability (ATC). The merits of 
these linear distribution factors lie in their fast and simple algorithms compared to traditional Newton-Raphson (N-R) load flow. Continuation Power Flow (CPF) is implemented by (Shaaban, Ni, \& Wu, 2000; Hur, Kim, B,H, \& Son, 2001). They incorporate the effects of reactive power flows, voltage limits and voltage collapse, and the traditional thermal loading effect. It can trace the power flow solution curve, starting at a base load, leading to the steady state voltage stability limit or the critical maximum loading point of the system. It overcomes the singularity of the Jacobian matrix close to the critical point. However, to increase a certain power transfer, CPF uses a common loading factor for a specific cluster of generator(s) and load(s), which might lead to a conservative TTC value since the optimal distribution of generation or loading is ignored. Besides, the implementation of CPF involves parameterization, predictor, corrector and step-size control, which are complicated. Since CPF increases the loading factor along certain directions without considering control effects, it may give conservative transfer capability results (Ou \& Singh, 2002). However the Optimal Power Flow (OPF) method can symmetrically handle the operational problems but since the approximation is used the accuracy of this calculation is low. It also causes convergence problems due to a huge number of variable and equations for large scale electric power systems. Optimal power flow with transient stability constraints was proposed by (Tuglie, Dicorato, Scala, \& Scarpellini, 2000; Chen, Tada, \& Okamoto, 2001) where the differential equations are used to define the domain. The security constrained OPF method (Hur, Park, K, \& Kim, 2003; Shaaban M. , Li, Yan, Ni, \& Wu, 2003; Gao, Zhou, M, \& Li, 2006), has also been used to solve the Steady-State Security Constrained (SSSC) ATC problem. However, the correct representation of security constraints (and even more so if post-contingency actions are to be taken into account) may cause a great increase of orders of magnitudes in problem size. OPF methods might be the most promising one for calculating TTC and should be given more considerable attention (Dai, McCalley, \& Vittal, 2000; Diao, Mohamed, \& Ni, 2000; Yue, Junji, \& Takeshi, 2003). Up till now, the OPF based techniques for TTC calculation are very slow and cannot be applied online yet. Therefore, developing a quick and accurate method for TTC calculation, which can effectively consider various likely contingencies and stability constraints, is still a technical challenge. Repeated Power Flow method (RPF) (Gao, Morison, \& Kundur, 1996; Ou \& Singh, 2003) repeatedly solves conventional power flow equations at a succession of points along the specified transfer directions while CPF solves a set of augmented power flow equations to obtain the solution curve passing through the nose point without encountering the numerical difficulty of ill-conditioning. Compared to any OPF method, $\mathrm{RPF}$ can provide P-V and V-Q curves for voltage stability studied. Moreover adjustment method of control variables in RPF is relatively easy. Compared to the CPF method, the implementation of RPF method is much easier and the time for convergence time is less (Gravener, Nwankpa, \& Yeoh, 1999).

The comparison of the performance of deterministic methods is listed in Table 1.1. This table shows the steady state constraints which are considered for deterministic ATC computation methods. Based on this table, DC power flow has been widely used to calculate deterministic ATC by thermal limit. However DC power flow cannot deal with other limiting factors. In PTDF, LODF and GSF methods, only thermal limitation could be taken into account too. However RPF, CPF and OPF could calculate the deterministic ATC with thermal, voltage and stability limitations. Therefore, the computation accuracy of these RPF, $\mathrm{CPF}$ and OPF are better than the DCPF, PTDF, LODF and GSF. 


\begin{tabular}{|c|c|c|c|}
\hline \multirow{2}{*}{ Method } & \multicolumn{3}{|c|}{ Constraints Considered } \\
\cline { 2 - 4 } & Thermal & Voltage & Stability \\
\hline DCPF & Yes & No & No \\
\hline PTDF & Yes & No & No \\
\hline LODF & Yes & No & No \\
\hline GSF & Yes & No & No \\
\hline RPF & Yes & Yes & Yes \\
\hline CPF & Yes & Yes & Yes \\
\hline OPF & Yes & Yes & Yes \\
\hline
\end{tabular}

Table 1.1. Performance Comparisons of Deterministic ATC Methods

\subsection{Review of Krylov subspace methods}

A Krylov subspace methods is one of the most important classes of iterative methods for solving linear algebraic systems, which are spanned by the initial residual and by vectors formed by repeated multiplication of the initial residual by the system matrix (Jorg Liesen, 2004). The Krylov subspace methods have been developed and perfected since early 1980's for the iterative solution of the linear problem $\mathrm{Ax}=\mathrm{b}$ for large, sparse and nonsymmetric Amatrices. The approach is to minimize the residual $r$ in the formulation of $r=b-A x$ (Kulkarnil, Pai, \& Sauer, 2001). Because these methods form a basis, it is clear that this method converges in $\mathrm{N}$ iterations when $\mathrm{N}$ is the matrix size. With more powerful computers and better methods it is possible to solve larger and more complex problem for the application ranging from quantum chromo dynamics to air control problems (Simoncini \& Szyld, 2007). Krylov subspace methods known as iterative methods among the "Top 10" algorithmic ideas of the 20th century for solving linear systems (Ciprara, 2000). This is due to the capability of Krylov subspace to be built using only a function that computes the multiplication of the system matrix and a vector. Hence, the system matrix itself will not be formed or sorted explicitly and it is suited for application in large and sparse linear systems (Jorg Liesen, 2004).

\subsection{Krylov subspace method applications in power system}

Recently, a set of Krylov subspace-based, reduced order modeling techniques have been introduced for the efficient simulation of large linear systems. These algorithms, which include the Pad'e via Lanczos (PVL) (Feldmann \& Freund, 1995), Arnoldi (Silveira, Kamon, \& White, 1995), and congruence transformation (Kerns, Wemple, \& Yang, 1995) processes, produce more accurate and higher order approximations compared to Automatic Waveform Evaluation (AWE) and its derivatives. Despite their superior performance to moment matching techniques, applications of Krylov subspace techniques have been limited to lumped RLC circuits (Mustafa \& Andreas, 1997). Preconditioned Krylov subspace iterative methods to perform fast DC and transient simulations for large-scale linear circuits with an emphasis on power delivery circuits was proposed by (Tsung Hao \& Charlie, 2001). Their method has been shown to be faster than traditional iterative methods without preconditioning. To take advantage of the fast convergence of these methods, the Nodal Analysis is proven to be feasible for general RLC circuits and the system matrix for transient simulation is indeed Symmetric Positive Definite (SPD), which is long believed not feasible. 
Krylov subspace was used by (Adam, 1996) method as iterative method, for the practical solution of the load flow problem. The approach developed was called the Kylov Subspace Power Flow (KSPF).

A continuation power flow method was presented by (Hiroyuki Mori, 2007) with the linear and nonlinear predictor based Newton-GMRES method to reduce computational time of the conventional hybrid method. This method used the preconditioned iterative method to solve the sets of linear equations in the N-R corrector. The conventional methods used the direct methods such as the LU factorization. However, they are not efficient for a largescaled sparse matrix because of the occurrence of the fill-in elements. On the other hand, the iterative methods are also more efficient if the condition number of the coefficient matrix in better. They employed generalized minimum residual (GMRES) method that is one of the Krylov subspace methods for solving a set of linear equations with a non symmetrical coefficient matrix. Their result shows, Newton GMRES method has a good performance on the convergence characteristics in comparison with other iterative methods and is suitable for the continuation power flow method.

\section{ATC computation}

\subsection{Introduction}

Transfer capability of a transmission system is a measure of unutilized capability of the system at a given time and depends on a number of factors such as the system generation dispatch, system load level, load distribution in network, power transfer between areas and the limit imposed on the transmission network due to thermal, voltage and stability considerations (Gnanadass, Manivannan, \& Palanivelu, 2003). In other words, ATC is a measure of the megawatt capability of the system over and above already committed uses.

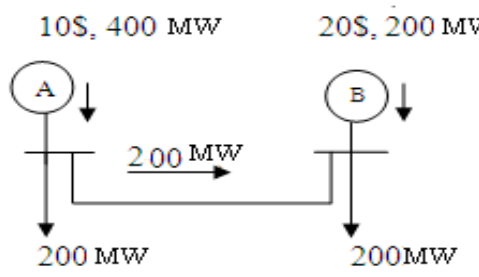

(a) Without Transfer Limitation
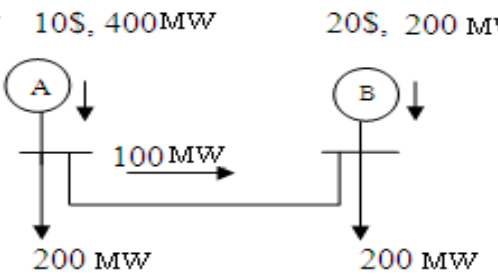

(b) With Transfer Limitation

Fig. 2.1. Power Transfer Capability between Two Buses

To illustrate the available transfer capability, a simple example of Figure 2.1 is used which shows a two bus system connected by a transfer line. Each zone has a $200 \mathrm{MW}$ constant load. Bus A has a $400 \mathrm{MW}$ generator with an incremental cost of $\$ 10 / \mathrm{MWh}$. Bus B has a 200 MW generator with an incremental cost of $\$ 20 / \mathrm{MWh}$ (Assuming both generators bid their incremental costs). If there is no transfer limit as shown in Figure 2.1(a), all $400 \mathrm{MW}$ of load will be bought from generator $\mathrm{A}$ at $\$ 10 / \mathrm{MWh}$, at a cost of $\$ 4000 / \mathrm{h}$. With $100 \mathrm{MW}$ transfer limitation (Figure 2.1(b)), then $300 \mathrm{MW}$ will be bought from $\mathrm{A}$ at $\$ 10 / \mathrm{MWh}$ and the remaining $100 \mathrm{MWh}$ must be bought from generator $\mathrm{B}$ at $\$ 20 / \mathrm{MWh}$, a total cost of $\$ 5000 / \mathrm{h}$. Congestion has created a market inefficiency about $25 \%$, even without strategic behavior by 
the generators. It has also created unlimited market power for generator B. B can also increase its bid as much as it wants, because the loads must still buy $100 \mathrm{MW}$ from it. Generator B's market power would be limited if there was an additional generator in zone B with a higher incremental cost, or if the loads had nonzero price elasticity and reduced their energy purchase as prices increased. In the real power system, cases of both limited and unlimited market power due to congestion can occur. Unlimited market power is probably not tolerable.

In another example of ATC calculation, Figure 2.2 shows two area systems. Where $\mathrm{P}_{\mathrm{gi}}$ and $\mathrm{P}_{\mathrm{gj}}$ are power generated in sending and receiving area. And $\mathrm{P}_{\mathrm{li}}$ and $\mathrm{P}_{\mathrm{lj}}$ are power utilized in sending and receiving area. In this case, ATC from sending area $i$ to the receiving area $j$, are determined at a certain state by Equation (2.1)

$$
\operatorname{ATC}_{\mathrm{ij}}=\left(\sum \mathrm{P}_{\mathrm{gi}}-\sum \mathrm{P}_{\mathrm{li}}\right)-\left(\sum \mathrm{P}_{\mathrm{gj}}-\sum \mathrm{P}_{\mathrm{lj}}\right)
$$

Where $\sum \mathrm{P}_{\mathrm{gi}}$ and $\sum \mathrm{P}_{\mathrm{gj}}$ are total power generated in the sending and receiving area. And $\sum \mathrm{P}_{\mathrm{li}}$ and $\sum \mathrm{P}_{\mathrm{lj}}$ are the total power utilized in the sending and receiving area. By applying a linear optimization method and considering ATC limitations, deterministic ATC can be determined. The block diagram of the general concept of deterministic is shown in Figure 2.3. These computational steps will be described in the following sections.

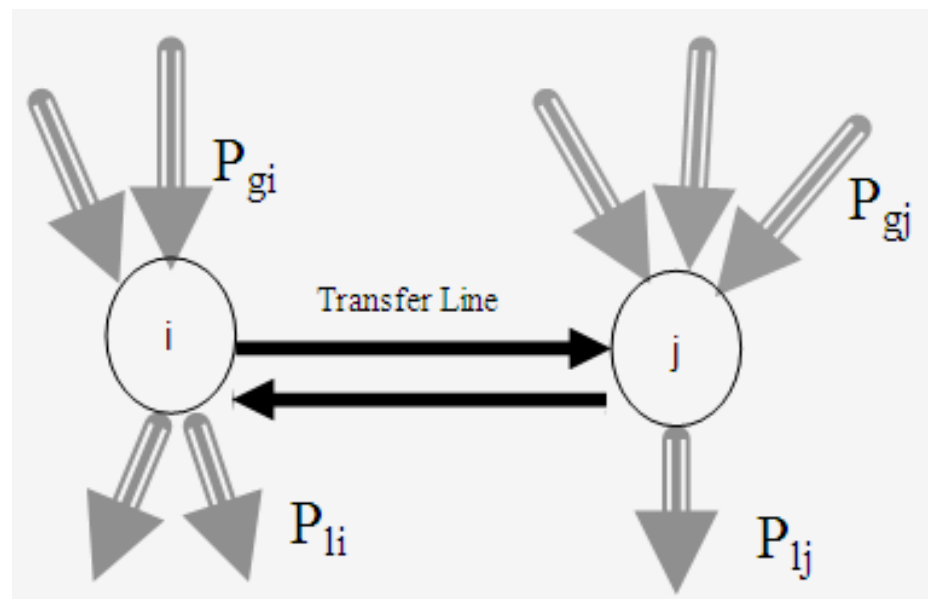

Fig. 2.2. Power Transfer between Two Areas

In this research, Equation (2.1) is employed to determine the ATC between two areas. Therefore, the ATC could be calculated for multilateral situation. The impact of other lines, generators and loads on power transfer could be taken into account. Then the ATC computation will be more realistic. Another benefit of this method is by using linear programming, which makes the ATC computations simple. Moreover the nonlinear behavior of ATC equations are considered by using one of the best iteration methods called Krylov subspace method. Critical line outage impact with time varying load for each bus is used directly to provide probability feature of the ATC. Therefore mean, standard deviation, skewness and kortusis are calculated and analyzed to explain the ATC for system planning. 


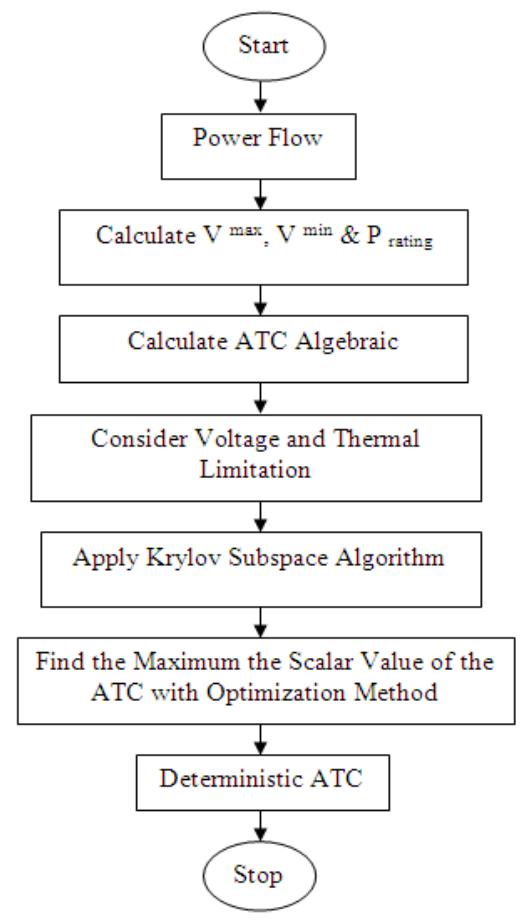

Fig. 2.3. The General Concept of the Proposed Algorithm for Deterministic ATC

\subsection{Deterministic ATC determination}

\subsubsection{Algebraic calculations}

In this section, $\mathrm{dP}_{\text {line }} / \mathrm{dp}_{\mathrm{ij}}$ and $\mathrm{d}|\mathrm{V}| / \mathrm{dp}_{\mathrm{ij}}$ are determined by using algebraic calculations, where $\mathrm{dP}_{\text {line }} / \mathrm{dp}_{\mathrm{ij}}$ and $\mathrm{d}|\mathrm{V}| / \mathrm{dp}_{\mathrm{ij}}$ are line flow power sensitivity factor and voltage magnitude sensitivity factor, and these give:

$$
\begin{gathered}
\left(\mathrm{dP}_{\text {line }} / \mathrm{dP}_{\mathrm{ij}}\right)=\operatorname{diag}\left(\mathrm{B}_{\text {line }}\right) \mathrm{L}\left(\mathrm{E}_{11}+\mathrm{E}_{12} \mathrm{PF}\right) \\
\left(\mathrm{d}|\mathrm{V}| / \mathrm{dP}_{\mathrm{ij}}\right)=\left(\mathrm{E}_{21}+\mathrm{E}_{22} \mathrm{PF}\right)
\end{gathered}
$$


Where $\operatorname{diag}\left(\mathrm{B}_{\text {line }}\right)$ represents a diagonal matrix whose elements are $\mathrm{B}_{\text {line }}$ (for each transmission line), $\mathrm{L}$ is the incident matrix, $\mathrm{PF}$ is the power factor, and $\mathrm{E}_{11}, \mathrm{E}_{12}, \mathrm{E}_{21}$ and $\mathrm{E}_{22}$ are the sub matrixes of inverse Jacobian matrix. This can be achieved by steps below (Hadi, 2002):

1. Define load flow equation by considering inverse Jacobian Equation (2.4) where inverse Jacobian sub matrixes are calculated from Equation (2.5).

2. Replace $\Delta \mathrm{Q}$ in Equation (2. 4) with Equation (2. 8) to set $\left(\mathrm{d}|\mathrm{V}| / \mathrm{dp}_{\mathrm{ij}}\right)$.

3. Use Equations (2.6) and (2.7) to set $\Delta \delta=\frac{\Delta \mathrm{P}_{\text {line }}}{\mathrm{LB}_{\text {line }}}$

4. Obtain $\left(\mathrm{dP}_{\text {line }} / \mathrm{dp}_{\mathrm{ij}}\right)$ from Equations (2. 4), (2.8) and step 3.

$$
\begin{gathered}
{\left[\frac{\Delta \delta}{\Delta|\mathrm{V}|}\right]=[\mathrm{J}]^{-1}\left[\frac{\Delta \mathrm{P}}{\Delta \mathrm{Q}}\right]} \\
{[\mathrm{J}]^{-1}=\left[\begin{array}{ll}
\mathrm{E}_{11} & \mathrm{E}_{12} \\
\mathrm{E}_{21} & \mathrm{E}_{22}
\end{array}\right]} \\
\Delta \mathrm{dP}_{\text {line }}=\left(\Delta \delta_{\mathrm{i}-} \Delta \delta_{\mathrm{j}}\right) \mathrm{B}_{\text {line }} \\
\Delta \delta=\left(\Delta \delta_{\mathrm{i}}-\Delta \delta_{\mathrm{j}}\right)=\mathrm{L} . \\
\Delta \mathrm{Q}=\text { PF. } \Delta
\end{gathered}
$$

Note: $\mathrm{L}$ is the incident matrix by (number of branch) * (number of lines) size and include 0,1 and -1 to display direction of power transferred.

Due to nonlinear behavior of power systems, linear approximation $\left(\mathrm{dP}_{\text {line }} / \mathrm{dp}_{\mathrm{ij}}\right)$ and $\left(\mathrm{d}|\mathrm{V}| / \mathrm{dp}_{\mathrm{ij}}\right)$ can yield errors in the value of the ATC. In order to get a more precise ATC, an

efficient iterative approach must be used. One of the most powerful tools for solving large and sparse systems of linear algebraic equations is a class of iterative methods called Krylov subspace methods. These iterative methods will be described comprehensively in Section 3.2.3. The significant advantages are low memory requirements and good approximation properties. To determine the ATC value for multilateral transactions the sum of ATC in Equation (2.9) must be considered,

$$
\sum_{\mathrm{k}} \mathrm{ATC}_{\mathrm{ij}} \quad, \mathrm{k}=1,2,3
$$

Where $\mathrm{k}$ is the total number of transactions.

\subsubsection{Linear Programming (LP)}

Linear Programming (LP) is a mathematical method for finding a way to achieve the best result in a given mathematical model for some requirements represented as linear equations. Linear programming is a technique to optimize the linear objective function, with linear 
equality and linear inequality constraints. Given a polytope and a real-valued affine function defined on this polytope, where this function has the smallest (or largest) value if such point exists, a Linear Programming method with search through the polytope vertices will find a point. A linear programming method will find a point on the polytope where this function has the smallest (or largest) value if such point exists, by searching through the polytope vertices. Linear Programming is a problem that can be expressed in canonical form (Erling D, 2001):

$$
\text { Maximize: } \mathrm{C}^{\mathrm{T}} \mathrm{x}
$$

Subject to: $\mathrm{Ax} \leq \mathrm{b}$

Where $x$ represents the vector of variables to be determined, $c$ and $b$ are known vectors of coefficients and $\mathrm{A}$ is a known matrix of coefficients. The $\mathrm{C}^{\mathrm{T}} \mathrm{x}$ is an objective function that requires to be maximized or minimized. The equation $A x \leq b$ is the constraint which specifies a convex polytope over which the objective function is to be optimized. Linear Programming can be applied to various fields of study. It is used most extensively in business, economics and engineering problems. In Matlab programming, optimization toolbox is presented to solve a linear programming problem as:

$$
\begin{gathered}
\min _{x} f_{x}^{T} \text { such that } A \cdot x \leq b \\
A_{e q} \cdot x=b_{e q} \\
l_{b} \leq x \leq u_{b}
\end{gathered}
$$

Where $f, x, b_{e q}, l_{b}$ and $u_{b}$ are matrices.

Example 1: Find the minimum of $f\left(x_{1}, x_{2}, x_{3}, x_{4}\right)=-3 x_{1}-6 x_{2}-8 x_{3}-9 x_{4}$ with $11 x_{1}-$ $5 x_{2}+3 x_{3}+2 x_{4} \leq 30,2 x_{1}+15 x_{2}+3 x_{3}+6 x_{4} \leq 12,3 x_{1}+8 x_{2}+7 x_{3}+4 x_{4} \leq 15$ and $9 x_{1}+$ $5 x_{2}+x_{3}+4 x_{4} \leq 30$ inequalies when $0 \leq x_{1}, x_{2}, x_{3}, x_{4}$.

To solve this problem, first enter the coefficients and next call a linear programming routine as new M-file:

$$
\begin{gathered}
f=[-3 ;-6,-8,-9] \\
A=\left[\begin{array}{cccc}
11 & -5 & 3 & 2 \\
2 & 15 & 3 & 6 \\
3 & 8 & 7 & 3 \\
9 & 5 & 1 & 4
\end{array}\right] ; \\
b=[30 ; 12 ; 15 ; 30] \\
l b=\operatorname{zeros}(4,1) ; \\
{[x]=\operatorname{linprog}(f, A, b,[\quad],[], l b)}
\end{gathered}
$$

The solution $x$ will be appeared in command windows as:

$$
\begin{array}{r}
x=0.0000 \\
0.0000 \\
1.6364 \\
1.1818
\end{array}
$$


As previous noted, ATC can be defined by linear optimization. By considering ATC calculation of Equation (2.1), the objective function for the calculation of ATC is formulated as (Gnanadass \& Ajjarapu, 2008):

$$
\mathrm{f}=\min \left(\left(\sum \mathrm{P}_{\mathrm{gj}}-\sum \mathrm{P}_{\mathrm{lj}}\right)-\left(\sum \mathrm{P}_{\mathrm{gi}}-\sum \mathrm{P}_{\mathrm{li}}\right)\right)
$$

The objective function measures the power exchange between the sending and receiving areas. The constraints involved include,

a. Equality power balance constraint. Mathematically, each bilateral transaction between the sending and receiving bus i must satisfy the power balance relationship.

$$
\mathrm{P}_{\mathrm{gi}}=\mathrm{P}_{\mathrm{lj}}
$$

For multilateral transactions, this equation is extended to:

$$
\sum_{\mathrm{i}} \mathrm{P}_{\mathrm{gi}}^{\mathrm{k}}=\sum_{\mathrm{j}} \mathrm{P}_{\mathrm{lj}}^{\mathrm{k}} \quad, \mathrm{k}=1,2,3 \ldots
$$

Where $k$ is the total number of transactions.

b. Inequality constraints on real power generation and utilization of both the sending and receiving area.

$$
\begin{aligned}
& \mathrm{P}_{\text {gi }}^{\text {base }} \leq \mathrm{P}_{\mathrm{gi}} \leq \mathrm{P}_{\mathrm{gi}}^{\max } \\
& \mathrm{P}_{\mathrm{lj}}^{\text {base }} \leq \mathrm{P}_{\mathrm{lj}} \leq \mathrm{P}_{\mathrm{lj}}^{\max }
\end{aligned}
$$

Where $\mathrm{P}_{\mathrm{gi}}^{\mathrm{base}}$ and $\mathrm{P}_{\mathrm{lj}}^{\text {base }}$ are the values of the real power generation and utilization of load flow in the sending and receiving areas, $\mathrm{P}_{\mathrm{gi}}^{\max }$ and $\mathrm{P}_{\mathrm{lj}}^{\max }$ are the maximum of real power generation and utilization in the sending and receiving areas.

c. Inequality constraints on power rating and voltage limitations.

With use of algebraic equations based load flow, margins for ATC calculation from bus i to bus $\mathrm{j}$ are represented in Equations (2.15 and 2.16) and Equations (2.18 and 2.19). For thermal limitations the equations are,

$$
\begin{aligned}
& \operatorname{ATC}_{\mathrm{ij}}\left(\frac{\mathrm{dP}_{\text {line }}}{\mathrm{dp}_{\mathrm{ij}}}\right)+\mathrm{P}_{\text {line }} \leq \mathrm{P}_{\max } \\
& -\mathrm{P}_{\max } \leq \operatorname{ATC}_{\mathrm{ij}}\left(\frac{\mathrm{dP}_{\text {line }}}{\mathrm{dp}_{\mathrm{ij}}}\right)+\mathrm{P}_{\text {line }}
\end{aligned}
$$

Where $\mathrm{P}_{\max }$ is determined as $\mathrm{P}_{\text {rating }}$ in Equation (2.17).

$$
\mathrm{P}_{\max }=\mathrm{P}_{\text {rating }}=\frac{\left|\mathrm{V}_{\mathrm{i}}\right|\left|\mathrm{V}_{\mathrm{j}}\right|}{\mathrm{X}_{\mathrm{ij}}}
$$

Where $V_{i}$ and $V_{j}$ are bus voltage of the sending and receiving areas. And $\mathrm{X}_{\mathrm{ij}}$ is the reactance between bus $i$ and bus $j$. For voltage limitations,

$$
\begin{aligned}
& \operatorname{ATC}_{\mathrm{ij}}\left(\frac{\mathrm{d}|\mathrm{V}|}{\mathrm{dp}_{\mathrm{ij}}}\right)+|\mathrm{V}| \leq|\mathrm{V}|_{\text {max }} \\
& |\mathrm{V}|_{\text {min }} \leq \mathrm{ATC}_{\mathrm{ij}}\left(\frac{\mathrm{d}|\mathrm{V}|}{\mathrm{dp}_{\mathrm{ij}}}\right)+|\mathrm{V}|
\end{aligned}
$$


Where $\mathrm{dP}_{\text {line }} / \mathrm{dp}_{\mathrm{ij}}$ and $\mathrm{d}|\mathrm{V}| / \mathrm{dp}_{\mathrm{ij}} \quad$ are calculated from Equations (2.2 and 2.3). Note:

Reactive power $(q)$ constraints must be considered as active power constraints in equations 2.11-2.14.

\subsubsection{Krylov subspace methods for ATC calculations}

Krylov subspace methods form the most important class of iterative solution method. Approximation for the iterative solution of the linear problem $A x=b$ for large, sparse and nonsymmetrical A-matrices, started more than 30 years ago (Adam, 1996). The approach was to minimize the residual $\mathrm{r}$ in the formulation $r=b-A x$. This led to techniques like, Biconjugate Gradients (BiCG), Biconjugate Gradients Stabilized (BICBSTAB), Conjugate Gradients Squared (CGS), Generalized Minimal Residual (GMRES), Least Square (LSQR), Minimal Residual (MINRES), Quasi-Minimal Residual (QMR) and Symmetric LQ (SYMMLQ).

The solution strategy will depend on the nature of the problem to be solved which can be best characterized by the spectrum (the totality of the eigenvalues) of the system matrix A. The best and fastest convergence is obtained, in descending order, for A being:

a. symmetrical (all eigenvalues are real) and definite,

b. symmetric indefinite,

c. nonsymmetrical (complex eigenvalues may exist in conjugate pairs) and definite real, and

d. nonsymmetrical general

However MINRES, CG and SYMMLQ can solve symmetrical and indefinite linear system whereas BICGSTAB, LSQR, QMR and GMRES are more suitable to handle nonsymmetrical and definite linear problems (Ioannis K, 2007). In order to solve the algebraic programming problem mentioned in Section 2.2.1 and the necessity to use an iterative method, Krylov subspace methods are added to the ATC computations. Therefore the ATC margins equations can be represented in the general form:

$$
\mathrm{f}(\mathrm{x})=0
$$

Where $x$ represents $\mathrm{ATC}_{\mathrm{ij}}$ vector form (number of branches) from Equations (2.15 and 2.16) and also $\mathrm{ATC}_{\mathrm{ij}}$ vector form (number of buses) of Equations (2.18 and 2.19). With iteration step $\mathrm{k}$, Equation (2.20) gives the residual $\mathrm{r}_{\mathrm{k}}$.

$$
r_{k}=f\left(x_{k}\right)
$$

And the linearized form is:

$$
\mathrm{r}_{\mathrm{k}}=\mathrm{b}-\mathrm{Ax}_{\mathrm{k}}
$$

Where A represents $\operatorname{diag}\left(\mathrm{dP}_{\text {line }} / \mathrm{dp}_{\mathrm{ij}}\right.$ ) or $\operatorname{diag}\left(\mathrm{d}|\mathrm{V}| / \mathrm{dp}_{\mathrm{ij}}\right)$ in diagonal matrix form (number of

branches) $\mathrm{x}$ (number of branches) or (number of buses) $\mathrm{x}$ (number of buses), and $\mathrm{b}$ gives $\mathrm{P}_{\text {rating }}-\mathrm{P}_{\text {line }}$ or $-\mathrm{P}_{\text {rating }}-\mathrm{P}_{\text {line }}$ in vector form (number of branches) and $|\mathrm{V}|_{\max }-|\mathrm{V}|$ or $|\mathrm{V}|-|\mathrm{V}|_{\text {min }}$ in vector form (number of buses) while the Equations $(2.15,2.16,2.18$ and 2.19) can be rewritten as in Equations (2.23- 2.26). In this case, the nature of $\mathrm{A}$ is nonsymmetrical 
and definite. However, all of the Krylov subspace methods can be used for ATC computation but BICGSTAB, LSQR, QMR and GMRES are more suitable to handle this case.

$$
\begin{aligned}
\mathrm{ATC}_{\mathrm{ij}} & =\frac{-\mathrm{P}_{\text {rating }}-\mathrm{P}_{\text {line }}}{\left(\mathrm{dP}_{\text {line }} / \mathrm{dp}_{\mathrm{ij}}\right)} \\
\mathrm{ATC}_{\mathrm{ij}} & =\frac{|\mathrm{V}|_{\text {max }}-|\mathrm{V}|}{\left(\mathrm{dV}_{\mathrm{d} p_{\mathrm{ij}}}\right)} \\
\mathrm{ATC}_{\mathrm{ij}} & =\frac{-\mathrm{P}_{\text {rating }}-\mathrm{P}_{\text {line }}}{\left(\mathrm{dP}_{\text {line }} / \mathrm{dp}_{\mathrm{ij}}\right)} \\
\mathrm{ATC}_{\mathrm{ij}} & =\frac{|\mathrm{V}|_{\text {min }}-|\mathrm{V}|}{\left(\mathrm{dV}_{\mathrm{dp}_{\mathrm{ij}}}\right)}
\end{aligned}
$$

Generalized Minimal Residual (GMRES) method flowchart is presented in Figure 2.5 as an example of Krylov subspace methods for solving linear equations iteratively. It starts with an initial guess value of $\mathrm{x}_{0}$ and a known vector $\mathrm{b}$ and $A$ matrix obtained from the load flow. A function then calculates the $A x_{0}$ using $\operatorname{diag}\left(\mathrm{dP}_{\text {line }} / \mathrm{dp}_{\mathrm{ij}}\right)$ or $\operatorname{diag}\left(\mathrm{d}|\mathrm{V}| / \mathrm{dp}_{\mathrm{ij}}\right)$. The GMRES subroutine then starts to iteratively minimize the residual $r_{k}=b-A x_{k}$. The program is then run in a loop up to some tolerance or until the maximum iteration is reached. At each step, when a new $r$ is determined, it updates the value of $x$ and asks the user to provide the $\mathrm{Ax}_{\mathrm{k}}$ using the updated value.

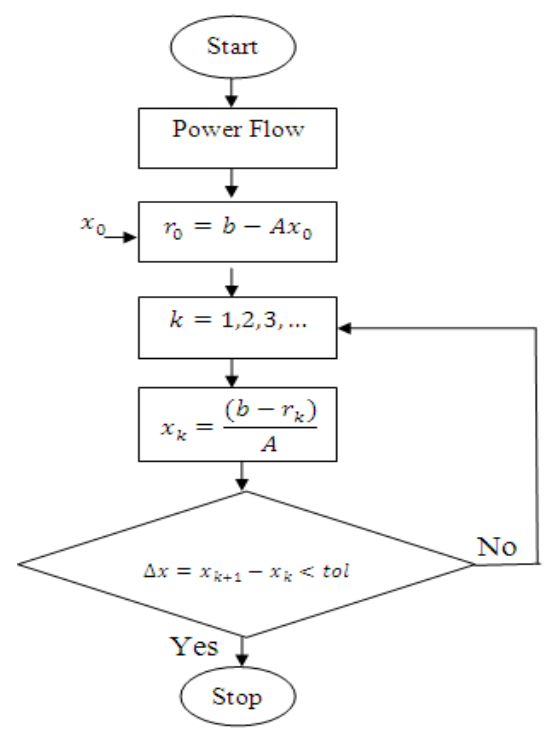

Fig. 2.5. Flowchart for GMRES Algorithm

In Matlab programming GMRES must be defined as $[x]=\operatorname{gmres}\left(A, b\right.$, restart, tol, maxit, $\left.M 1, M 2, X_{0}\right)$. This function attempts to solve the 
system of linear equations $A * x=b$ for $x$. Then $\mathrm{n}$ by n coefficient matrix $A$ must be square and should be large and sparse. Then column vector $\mathrm{b}$ must have length $\mathrm{n}$. $A$ can be a function handle afun such that afun(x) returns $A * x$. If GMRES converges, a message to that effect is displayed. If GMRES fails to converge after the maximum number of iterations or halts for any reason, a warning message is printed displaying the relative residual norm $(b-A * x) / \operatorname{norm}(b)$ and the iteration number at which the method stopped or failed. GMRES restarts the method in every inner iteration. The maximum number of outer iterations is $\min (n /$ restart,$n)$. If restart is $n$ or [ ], then GMRES does not restart and the maximum number of total iterations is $\min (n, 10)$. In GMRES function," tol" specifies the tolerance of the method. If "tol" is [ ], then GMRES uses the default, $1 e-6$. "maxit specifies the maximum number of outer iteration, i.e., the total number of iteration does not exceed restart*maxit. If maxit is [ ] then GMRES uses the default, $\min (n /$ restart, 10$)$. If restart is $\mathrm{n}$ or [ ], then the maximum number of total iterations is maxit (instead of restart*maxit). "M1" and "M2" or M=M1*M2 are preconditioned and effectively solve the system $\operatorname{inv}(M) * A * x=\operatorname{inv}(M) * b$ for $x$. If $\mathrm{M}$ is [ ] then GMRES applies no preconditioned. $\mathrm{M}$ can be a function handle $m f$ un such that $m f u n(x)$ returns $(M \backslash x)$. Finally, $x_{0}$ specifies the first initial guess. If $x_{0}$ is [ ], then GMRES uses the default, an all zero vector.

\section{Result and discussion}

In this section, illustrations of ATC calculations are presented. For this purpose the IEEE 30 and IEEE 118 (Kish, 1995) bus system are used. In the first the residual, CPU time and the deterministic ATC are obtained based on Krylov subspace methods and explained for IEEE 30 and IEEE 118 bus system. Finally the deterministic ATC results of IEEE 30 bus system are compared with other methods. The deterministic ATC calculation is a significant part of the probabilistic ATC calculation process. Therefore, it is important that the deterministic ATC formulation is done precisely. For the first step, the deterministic ATC equations shown in Section 2.2 are used for IEEE 30 and IEEE 118 bus system to find the deterministic ATC.

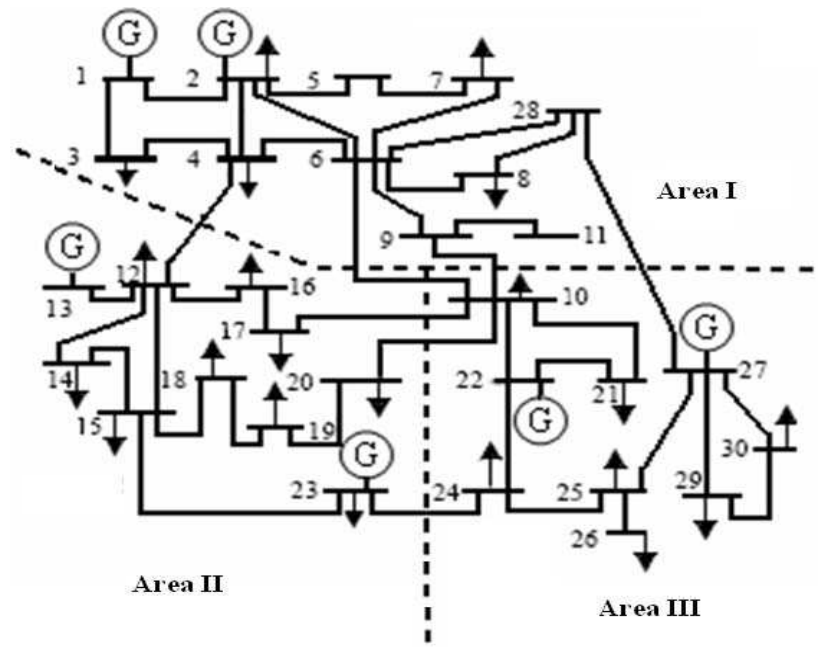

Fig. 3.1. IEEE 30 Bus System 
IEEE 30 bus system (Figure 3.1) comprises of 6 generators, 20 load buses and 41 lines, and IEEE 118 bus system (Figure 3.3) has 118 buses, 186 branches and 91 loads. All computations in this study were performed on $2.2 \mathrm{GHz}$ RAM, 1G RAM and 160 hard disk computers. Because of the nonlinear behavior of load flow equations, the use of iterative methods need to be used for the ATC linear algebraic equations. One of the most powerful tools for solving large and sparse systems of linear algebraic equations is a class of iterative methods called Krylov subspace methods. The significant advantages of Krylov subspace methods are low memory requirements and good approximation properties. Eight Krylov subspace methods are mentioned in Section 2.2.3. All of these methods are defined in MATLAB software and could be used as iteration method for deterministic ATC calculation.

The CPU time is achieved by calculating the time taken for deterministic ATC computation by using Krylov subspace methods for IEEE 30 and IEEE 118 bus systems using MATLAB programming. The CPU time results are shown in Figure 3.2. In Figure 3.2, the CPU time for eight Krylov methods mentioned in Section 2.2.3 are presented. Based on this result, the CPU times of ATC computation for IEEE 30 bus system range from $0.75-0.82$ seconds. The CPU times result for IEEE 118 bus system is between $10.18-10.39$ seconds.

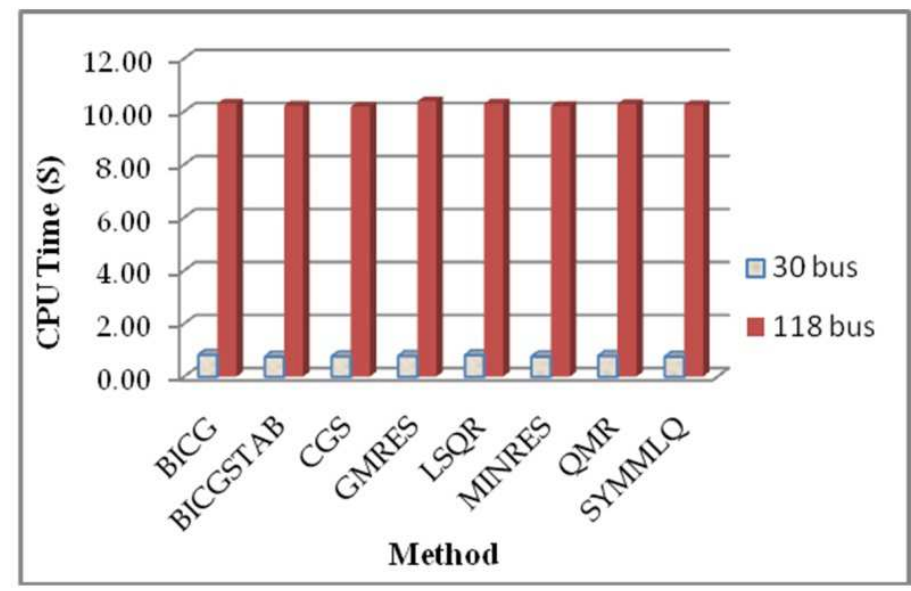

Fig. 3.2. CPU Time Comparison of Krylov Subspace Methods for Deterministic ATC (IEEE 30 and 118 bus system)

The computation of residual is done in MATLAB programming for each of Krylov subspace methods. The residual $r_{k}$ is defined in Equation (2.21). A sample result in MATLAB is shown in Figure 3.5 using LSQR and SYMMLQ for IEEE 30 bus system. The number of iteration and residual of the deterministic ATC computation are shown in this figure. Figure 3.4 presents the residual value of the ATC computations by applying each of Krylov subspace methods for IEEE 30 and 118 bus system. One of the most important findings of Figure 4.4 is the result obtained from the LSQR, which achieved a residual around $1.01 \times$ $10^{-10}$ and $5.3 \times 10^{-10}$ for IEEE 30 and 118 bus system respectively. According to this figure, it indicates that the residual of LSQR is very different from others. CGS in both system and BICGSTAB in IEEE 118 bus system have highest residual. However other results are in the same range of around $1.8 \times 10^{-8}$. Other performance of Krylov subspace methods like number of iteration are shown Tables 3.1 and 3.2. 


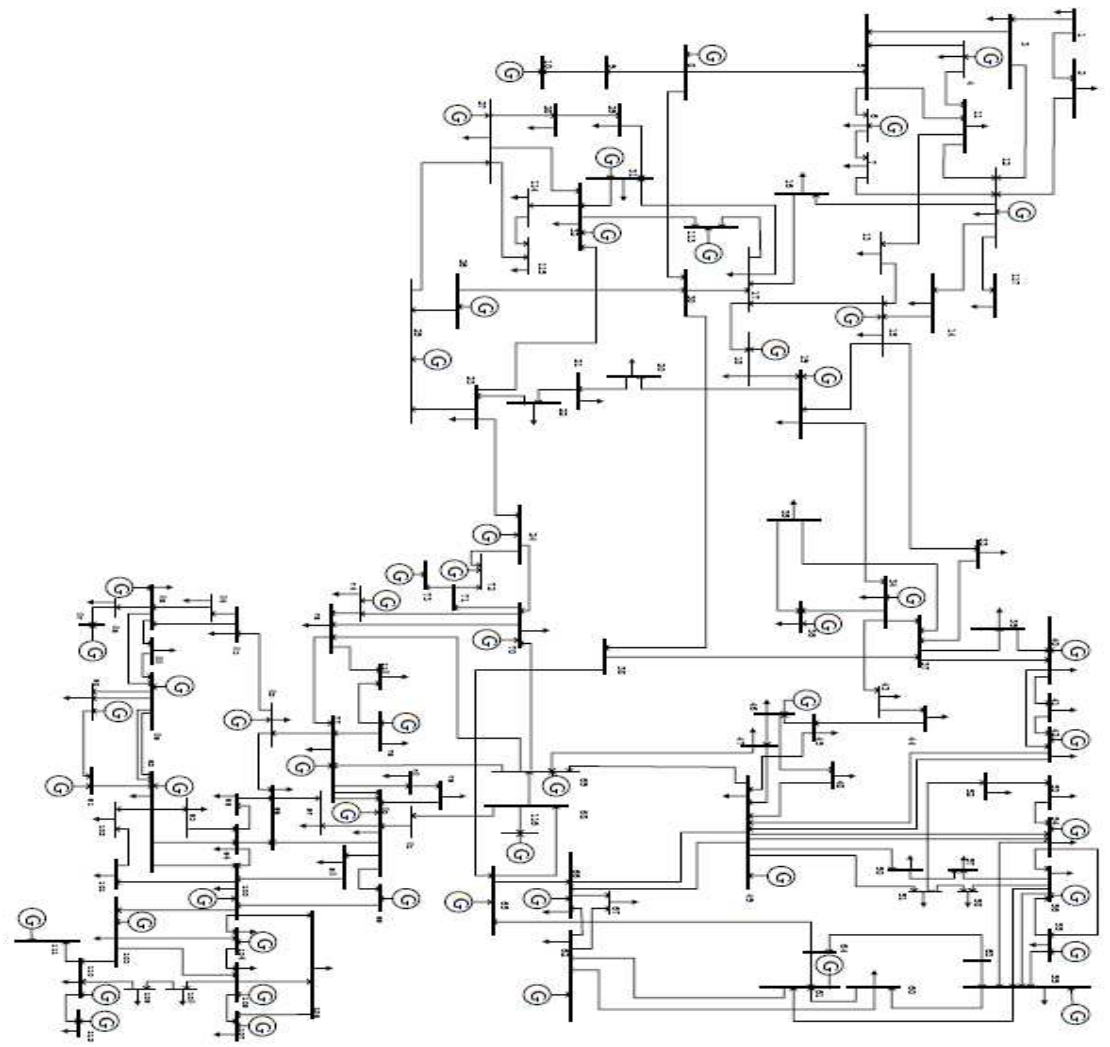

Fig. 3.3. IEEE 118 Bus System

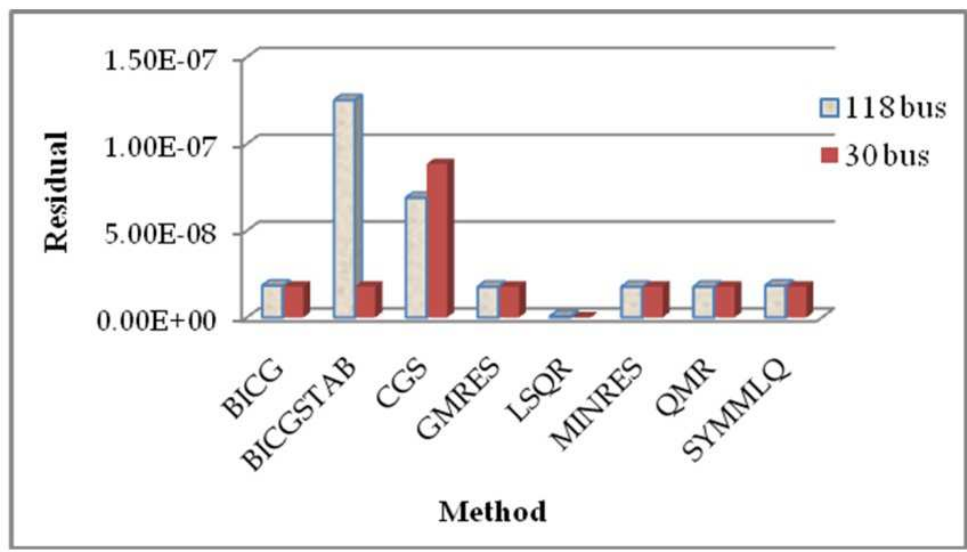

Fig. 3.4. Residual Comparison of Krylov Subspace Methods for Deterministic ATC (IEEE 30 and 118 bus system) 


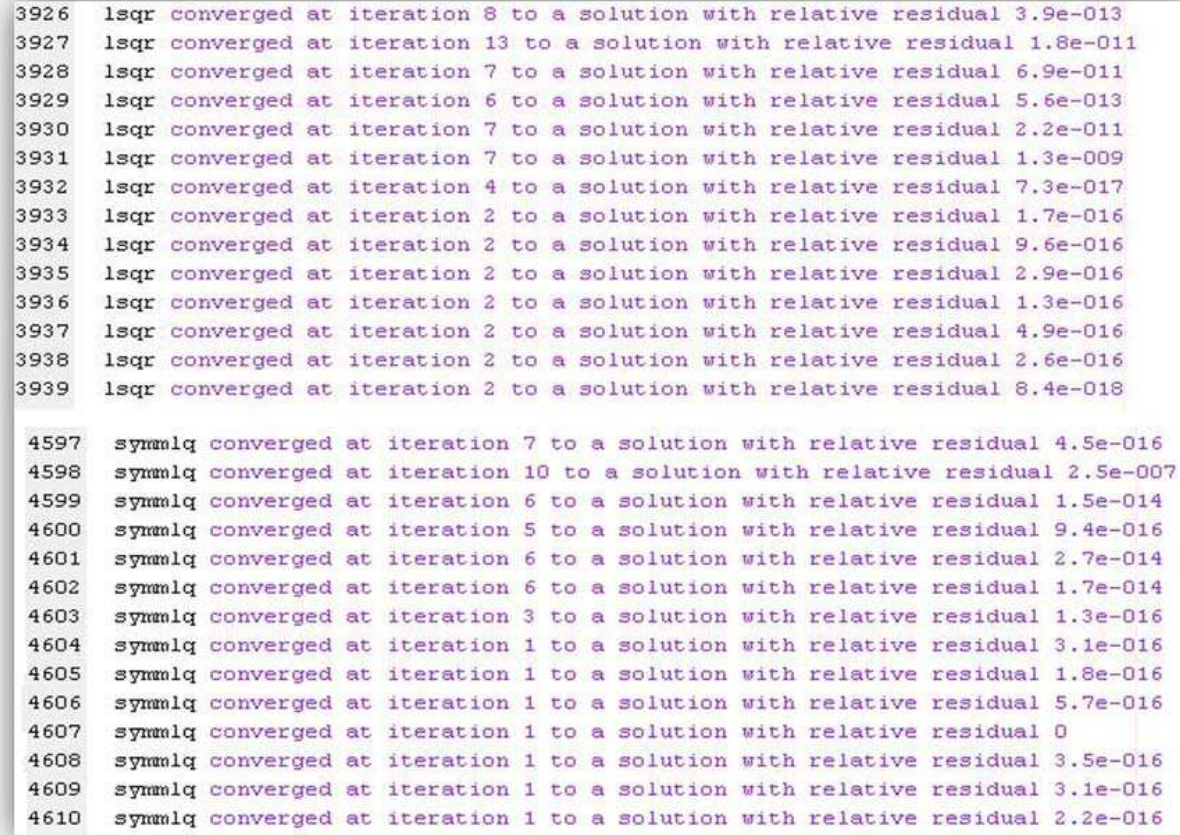

Fig. 3.5. Matlab Programming Results for LSQR and SYMMLQ Methods (IEEE 30 bus system)

Linear optimization mentioned in Section 2.2.2 is applied to the deterministic ATC calculation with all the constraints considered. The important constraints for calculating ATC are voltage and thermal rating. In these calculations the minimum and the maximum voltage are considered between $0.94-1.04$ of the base voltage for all the bus voltages. The thermal limitation is determined from Equations (2.15 and 2.16) of Section 2.2.2. In this computation, it was assumed that the voltage stability is always above the thermal and voltage constraints and reactive power demands at each load buses are constant.

Deterministic ATC results are represented in Tables 3.1 and 3.2 for IEEE 30 and IEEE 118 bus system. Each of these systems have 3 transaction paths as shown in Figures 3.1 and 3.6, the first one is between area 1 and area 2 (called T1), the second one is between area 1 and area 3 (called T2) and last one is between area 2 and area 3 (called T3). Residual, number of iteration and CPU time results are shown in columns 2, 3 and 4 of Tables 3.1 and 3.2 for IEEE 30 and 118 bus system. According to the results of ATC for T1, T2 and T3 in columns 5, 6 and 7 of these tables, the amount of the ATC of IEEE 30 bus system, is the same for all Krylov subspace methods which are 106.814, 102.925 and 48.03 MW for three transaction paths. The difference between the residuals in IEEE 118 bus system appears in the amount of ATC especially for T2 in Table 3.2. By comparing the performance results of Krylov subspace methods in Tables 3.1 and 3.2, it seems the result 
of LSQR is more appropriate to be used for ATC computations because of the low residual. This is related to generate the conjugate vectors $\omega_{i}$ from the orthogonal vectors $v_{i}$ via an orthogonal transformation in LSQR algorithm. LSQR is also more reliable in variance circumstance than the other Krylov subspace methods (Christopher \& Michael, 1982).

\begin{tabular}{|c|c|c|c|c|c|c|}
\hline \multirow{2}{*}{$\begin{array}{c}\text { Krylov } \\
\text { Subspace } \\
\text { Methods }\end{array}$} & Residual & \multirow{2}{*}{$\begin{array}{c}\text { Iteration } \\
\text { Number }\end{array}$} & $\begin{array}{c}\text { CPU Time } \\
(S)\end{array}$ & \multicolumn{3}{|c|}{ Deterministic ATC(MW) } \\
\cline { 5 - 7 } & & & T1 & T2 & T3 \\
\hline BICG & $1.79 \mathrm{E}-08$ & 5 & 0.82 & 106.814 & 102.925 & 48.030 \\
\hline BICGSTAB & $1.79 \mathrm{E}-08$ & 4 & 0.75 & 106.814 & 102.925 & 48.030 \\
\hline CGS & $8.84 \mathrm{E}-08$ & 4 & 0.76 & 106.814 & 102.925 & 48.030 \\
\hline GMRES & $1.79 \mathrm{E}-08$ & 5 & 0.78 & 106.814 & 102.925 & 48.030 \\
\hline LSQR & $1.01 \mathrm{E}-10$ & 5 & 0.81 & 106.814 & 102.925 & 48.030 \\
\hline MINRES & $1.79 \mathrm{E}-08$ & 4 & 0.76 & 106.814 & 102.925 & 48.030 \\
\hline QMR & $1.79 \mathrm{E}-08$ & 5 & 0.78 & 106.814 & 102.925 & 48.030 \\
\hline SYMMLQ & $1.79 \mathrm{E}-08$ & 4 & 0.75 & 106.814 & 102.925 & 48.030 \\
\hline
\end{tabular}

Table 3.1. Performance of Krylov Subspace Methods on Deterministic ATC for IEEE 30 Bus System

\begin{tabular}{|c|c|c|c|c|c|c|}
\hline \multirow{2}{*}{$\begin{array}{c}\text { Krylov } \\
\text { Subspace }\end{array}$} & Residual & Iteration & \multirow{2}{*}{$\begin{array}{c}\text { CPU } \\
\text { Number }\end{array}$} & Time (S) & \multicolumn{2}{|c|}{ Deterministic ATC(MW) } \\
\cline { 5 - 7 } & & & $\mathrm{T} 1$ & $\mathrm{~T} 2$ & $\mathrm{~T} 3$ \\
\hline BICG & $1.83 \mathrm{E}-08$ & 5 & 10.30 & 426.214 & 408.882 & 773.551 \\
\hline BICGSTAB & $1.25 \mathrm{E}-07$ & 4 & 10.22 & 426.214 & 143.846 & 773.532 \\
\hline CGS & $6.89 \mathrm{E}-08$ & 4 & 10.18 & 426.214 & 408.849 & 773.532 \\
\hline GMRES & $1.77 \mathrm{E}-08$ & 5 & 10.39 & 426.214 & 408.886 & 773.551 \\
\hline LSQR & $5.38 \mathrm{E}-10$ & 5 & 10.29 & 426.214 & 408.882 & 773.551 \\
\hline MINRES & $1.77 \mathrm{E}-08$ & 4 & 10.20 & 426.214 & 397.986 & 773.551 \\
\hline QMR & $1.77 \mathrm{E}-08$ & 5 & 10.28 & 426.214 & 408.882 & 773.551 \\
\hline SYMMLQ & $1.83 \mathrm{E}-08$ & 4 & 10.24 & 426.214 & 409.066 & 773.551 \\
\hline
\end{tabular}

Table 3.2. Performance of Krylov Subspace Methods on Deterministic ATC for IEEE 118 Bus System 


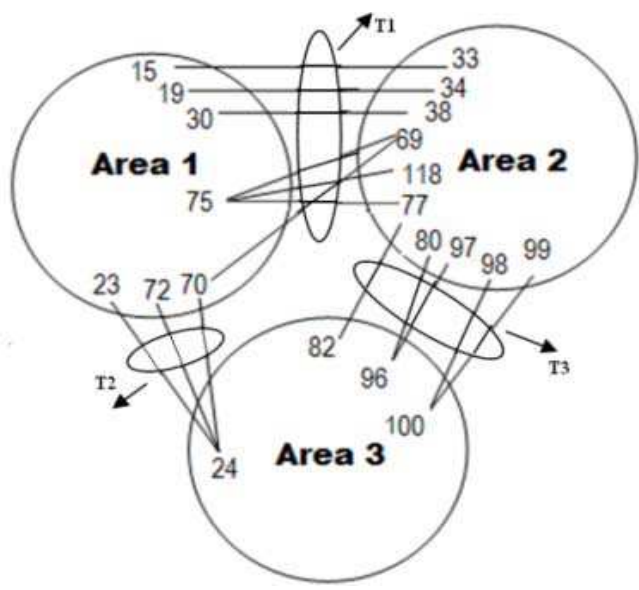

Fig. 3.6. Transaction Lines between Areas - IEEE 118 Bus System

\section{Conclusion}

The major contribution from this chapter is the application of the Krylov subspace methods to improve the ATC algebraic computations by using linear calculations for nonlinear nature of power system by Matlab programming. Eight Krylov subspace methods were used for ATC calculation and tested on IEEE 30 bus and IEEE 118 bus systems. The CPU time and residual were measured and compared to select the most appropriate method for ATC computation. Residual is an important parameter of Krylov subspace methods which help the algorithm to accurately determine the correct value to enable the corrector to reach the correct point. In these Krylov subspace techniques, there are no matrix factorizations and only space matrix-vector multiplication or evaluation of residual is used. This is the main contributing factor for its efficiency which is very significant for large systems. Deterministic ATC results for all Krylov subspace were done and their results comparison indicated that the amount of ATC for IEEE 30 bus system did not show significant change. For IEEE 118 bus system, because of the difference in residuals, different ATC were obtained. Unlike the other ATC algebraic computation methods, Krylov Algebraic Method (KAM) determined ATC for multilateral transactions. For this, the effects of lines, generators and loads were considered for ATC computation.

\section{References}

Adam, S. (1996). Fundamental Concepts of a Krylov Subspace Power Flow Methodology. IEEE Transactions on Power Systems , 11 (3), 1528 - 1537.

Chen, L., Tada, Y., \& Okamoto, H. (2001). Optimal Operation Solutions of Power Systems with Transient Stability Constraints. IEEE Transactions on Circuits and Systems , 48 (3), 327-339.

Christopher, C., \& Michael, A. (1982). LSQR: An Algorithm for Sparse Linear Equations and Sparse Least Squares. ACM Transactions on Mathematical Software , 8 (1), 43-71.

Ciprara, B. (2000). The Best of The 20th Century: editors Name Top 10 Algorithm. Society for Industrial and Applied Mathematics (SIAM) , 33 (4), 1. 
Dai, Y., McCalley, J. D., \& Vittal, V. (2000). Simplification Expansion and Enhancement of Direct Interior Point Algorithm for Power System Maximum Load Ability. IEEE Transactions on Power Systems , 15 (3), 1014 - 1021.

Diao, Q., Mohamed, S., \& Ni, Y. (2000). Inter-area Total Transfer Capability Calculation Using Sequential Quadratic Programming Method in Power Market. Automation of Electric Power Systems , 24 (24), 5-8.

Erling D, A. (2001). Linear optimization: Theory, Methods, and Extensions. EKA Consulting APS. Feldmann, P., \& Freund, R. W. (1995). Efficient Linear Circuit Analysis by Pad'e Approximation Via the Lancsoz Process. IEEE Transactions on Computer-Aided Design , 14 (5), 639-649.

FERC. (1996). Open Access Same-Time Information System and Standards of Conduct. Federal Energy Regulatory Commission.

Flueck, A. J., Chiang, H. D., \& Shah, K. S. (1996). Investigation the Installed Real Power Transfer Capability of a Large Scale Power System Under a Proposed Multiarea Interchange Schedule Using CPFLOW. IEEE Transaction on Power Systems, 11 (2), $883-889$.

Gao, B., Morison, G., \& Kundur, P. (1996). Towards the Development of a Systematic Approach for Voltage Stability Assessment of Large-Scale Power Systems. IEEE Transactions on Power Systems , 11 (3), 1314 - 1324.

Gao, Zhou, Y., M, \& Li, G. (2006). Sequential Monte Carlo Simulation Based Available Transfer Capability Calculation. International Conference on Power System Technology, (pp. 1-6). Chongqing .

Ghawghawe, Thakre, N., \& L, K. (2006). Application of Power Flow Sensitivity Analysis and PTDF for Determination of ATC. IEEE International Conference on Power Electronics, Drives and Energy Systems. New Delhi.

Gisin, B.S, O., M.V., \& Mitsche, J. (1999). Practical Methods for Transfer Limit Analysis in the Power Industry Deregulated Environment. Power Industry Computer Applications, (pp. 261-266). Santa clara CA.

Gnanadass, R., \& Ajjarapu, V. (2008). Assessment of Dynamic Available Transfer Capability using FDR PSO Algorithm. Elektrika Journal of Electrical Engineering , 10 (1), 20-25.

Gnanadass, R., Manivannan, K., \& Palanivelu, T. (2003). Assessment of Available Transfer Capability for Practical Power Systems with Margins. Conference on Convergent Technologies for Asia-Pacific Region, 1, pp. 445 - 449.

Gravener, M., Nwankpa, H. C., \& Yeoh, T. (1999). ATC Computational Issues. International Conference on Power System, (pp. 1-6). Hawaii.

Hadi, S. (2002). Power Systems Analysis, Second Edition. McGraw-Hill.

Hamoud, G. (2000). Feasibility Assessment of Simultaneous Bilateral Transactions in a Deregulated Environment. IEEE Transaction on Power System , 15 (1), 22-26.

Hiroyuki Mori, a. K. (2007). Continuation Newton-GMRES Power Flow with Linear and Nonlinear Predictors. Large Engineering Systems Conference on Power Systems, (pp. 171 - 175).

Hur, D. P., Kim, J. K., B,H, \& Son, K. M. (2001). Security Constrained Optimal Power Flow for the Evaluation of Transmission Capability on Electric Power System. Vancouver: Power Engineering Society Summer Meeting. 
Hur, Park, D., K, J., \& Kim, B. H. (2003). Application of Distributed Optimal Power Flow to Power System Security Assessment. Electrical Power Components System , 31 (1), 71 80.

Ilic, M., Yoon, Y., \& Dept, A. (1997). Available Transmission Capacity (ATC) and Its Value Under Open Access. IEEE Transaction on Power Systems , 12 (2), 636 - 645.

Ioannis K, A. (2007). Computational Theory of Iterative Methods (Vol. 15). Elsevier.

Jorg Liesen, P. T. (2004). Convergence Analysis of Krylov Subspace Methods. GAMMMitteilungen , 27 (2), 153-173.

Kerns, K. J., Wemple, I. L., \& Yang, A. T. (1995). Stable and Efficient Reduction of Substrate Model Networks Using Congruence Transforms. IEEE/ACM International Conference on Computer-Aided Design, (pp. 207-214).

Kish, L. (1995). Survey Sampling. New York: John Wiley \& Sons.

Kulkarnil, A. y., Pai, M. A., \& Sauer, P. W. (2001). Iterative Solver Techniques in Fast Dynamic Calculations of Power Systems. International Journal of Electrical Power \& Energy Systems , 23 (3), 237-244.

Kumar, A., Srivastava, S. C., \& Singh, S. N. (2004). Available Transfer Capability (ATC) Determination in a Competitive Electricity Market Using AC Distribution Factors. Electric Power Components and Systems, 32 (9), 927-939.

Li, C., \& Liu, C. (2002). A New Algorithm for Available Transfer Capability Computation. International Journal of Electric Power Energy System , 24 (2), 159-66.

Merryl, H. (1998). Probabilistic Available Capacity. IEEE PES Winter Meeting.

Mustafa, C., \& Andreas, C. C. (1997). Simulation of Multiconductor Transmission Lines Using Krylov Subspace Order-Reduction Techniques. IEEE Transactions on Computer-Aided Design and Systems , 16 (5), 485-496.

NERC, R. (1995). Available Transfer Capability Definitions and Determinations. North American Electric Reliability Council.

NERC, R. (1996). Available Transfer Capability Definitions and Determinations. North American Electric Reliability Council.

NERC, R. (1996). Promoting Utility Competition Through Open Aces, Non-Discriminatory Transmission Service by Public Utilities: Recovery of Standard Cost by Public Utilities and Transmission Utilities. Federal Energy Regulatory Commission.

Ou, Y., \& Singh, C. (2002). Assessment of Available Transfer Capability and Margins. IEEE Transaction on Power Systems , 17 (2), 463-468.

Ou, Y., \& Singh, C. (2003). Calculation of Risk and Statistical Indices Associated with Available Transfer : Generation, Transmission and Distribution. IEE Proceedings, 50, pp. 239 - 244. College Station, TX, USA.

Sakis Meliopoulos, A. P., Wook Kang, S., \& Cokkinides, G. (2000). Probabilistic Transfer Capability Assessment in a Deregulated Environment. IEEE Proc.International Conference on System Sciences. Hawaii.

Sauer, P., \& Grijalva, S. (1999). Error Analysis in Electric Power System Available Transfer Capability Computation. Decision Support Systems , 24 (3-4), 321-330.

Shaaban, M., Li, W., Yan, Z., Ni, Y., \& Wu, F. (2003). Calculation of Total Transfer Capability Incorporating the Effect of Reactive Power. Electric Power Systems Research, 64 (3), 181-188.

Shaaban, M., Ni, Y., \& Wu, F. (2000). Transfer Capability Computations in Deregulated Power Systems. International Conference on System Sciences, (pp. 1-5). Hawaii. 
Silveira, L. M., Kamon, M., \& White, J. (1995). Efficient Reduced-Order Modeling of Frequency-Dependent Coupling Inductances Associated with 3-D Interconnect Structures. IEEE Design Automation Conference, 19, pp. 376-380.

Simoncini, V., \& Szyld, D. (2007). Recent Computational Developments in Krylov Subspace Methods for Linear Systems. Numerical Linear Algebra Application, 14, 1-59.

Tsung Hao, C., \& Charlie, C. P. (2001). Efficient Large-Scale Power Grid Analysis Based on Preconditioned Krylov-Subspace Iterative Methods. Conference on Design Automation, (pp. 559-562). Las Vegas,Nevada, USA.

Tuglie, E. D., Dicorato, M., Scala, M. L., \& Scarpellini, P. (2000). A Static Optimization Approach to Access Dynamic Available Transfer Capability. IEEE Tranactions on Power Systems , 15 (3), 1069-1076.

Venkatesh, P., R, G., \& Prasad, P. (2004). Available Transfer Capability Determination Using Power Distribution Factors. Journal of Emerging Electric Power Systems , 1 (2), Article 1009.

Wood, A. (1996). Power Generation Operation and Control. New York: Willey.

Yang, L., \& Brent, r. (2001). The Improved Conjugate Gradient Squared (ICGS) Method on Parallel Distributed Memory Artitectures. Workshop Proceedings of the International Conference on Parallel Processing (ICPP-HPSECA01). Valencia, Spain.

Yue, Y., Junji, K., \& Takeshi, N. (2003). A Solution of Dynamic Available Transfer Capability by means of Stability Constrained Optimal Power Flow. IEEE Bologna Power Tech, (p. 8). Bologna. 


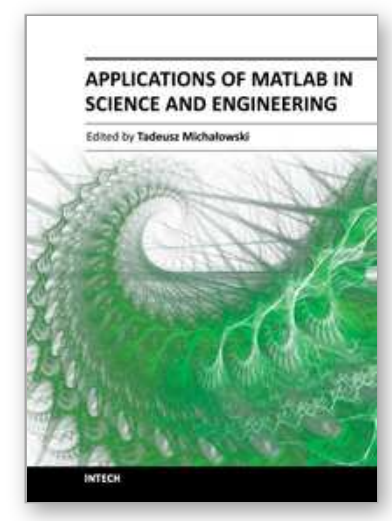

\section{Applications of MATLAB in Science and Engineering \\ Edited by Prof. Tadeusz Michalowski}

ISBN 978-953-307-708-6

Hard cover, 510 pages

Publisher InTech

Published online 09, September, 2011

Published in print edition September, 2011

The book consists of 24 chapters illustrating a wide range of areas where MATLAB tools are applied. These areas include mathematics, physics, chemistry and chemical engineering, mechanical engineering, biological (molecular biology) and medical sciences, communication and control systems, digital signal, image and video processing, system modeling and simulation. Many interesting problems have been included throughout the book, and its contents will be beneficial for students and professionals in wide areas of interest.

\section{How to reference}

In order to correctly reference this scholarly work, feel free to copy and paste the following:

Mojgan Hojabri and Hashim Hizam (2011). Available Transfer Capability Calculation, Applications of MATLAB in Science and Engineering, Prof. Tadeusz Michalowski (Ed.), ISBN: 978-953-307-708-6, InTech, Available from: http://www.intechopen.com/books/applications-of-matlab-in-science-and-engineering/available-transfercapability-calculation

\section{INTECH}

open science | open minds

\author{
InTech Europe \\ University Campus STeP Ri \\ Slavka Krautzeka 83/A \\ 51000 Rijeka, Croatia \\ Phone: +385 (51) 770447 \\ Fax: +385 (51) 686166 \\ www.intechopen.com
}

\author{
InTech China \\ Unit 405, Office Block, Hotel Equatorial Shanghai \\ No.65, Yan An Road (West), Shanghai, 200040, China \\ 中国上海市延安西路65号上海国际贵都大饭店办公楼 405 单元 \\ Phone: +86-21-62489820 \\ Fax: $+86-21-62489821$
}


(C) 2011 The Author(s). Licensee IntechOpen. This chapter is distributed under the terms of the Creative Commons Attribution-NonCommercialShareAlike-3.0 License, which permits use, distribution and reproduction for non-commercial purposes, provided the original is properly cited and derivative works building on this content are distributed under the same license. 